\title{
Microstructural Characterization and Corrosion Behavior of Electroless Ni-Zn-P Thin Films
}

\author{
Ionuţ Constantin \\ National RङD Institute for Nonferrous and Rare Metals (IMNR), 102 Biruinţei Boulevard, Pantelimon, 077145 Ilfov, Romania \\ Correspondence should be addressed to Ionuţ Constantin; iconstantin@imnr.ro
}

Received 31 October 2013; Revised 17 December 2013; Accepted 17 December 2013; Published 27 January 2014

Academic Editor: Menahem Bamberger

Copyright (C) 2014 Ionuţ Constantin. This is an open access article distributed under the Creative Commons Attribution License, which permits unrestricted use, distribution, and reproduction in any medium, provided the original work is properly cited.

Ternary Ni-Zn-P alloy thin films were electrolessly deposited on a carbon steel substrate from sulphate alkaline baths. The effect of deposition bath composition and process duration on the physical-chemical and corrosion characteristics of the obtained thin films was investigated. The thin films were characterized by EDAX analysis techniques and scanning electronic microscopy. Corrosion tests were performed in $3.5 \%$ sodium chloride solution and the corrosion current values were determined to be $4-12 \mu \mathrm{A}$, comparative to $15 \mu \mathrm{A}$ for the uncoated steel sample.

\section{Introduction}

Due to high corrosion resistance, cadmium is used extensively as an anticorrosive protection layer for steel components used in energetics, transportation, chemical equipment production, metallic constructions, and so forth [1]. However, cadmium plating presents major inconvenients due to metal toxicity and used salts as well as simultaneous discharge of hydrogen ions during the cadmiation process, making cadmiated parts susceptible of acid brittleness $[2,3]$. These are the main reasons why, in the last decades, intense studies and researches were performed for finding replacements for Cd based anticorrosive protection coatings.

An efficient alternative for sacrificial layers acting as replacements for $\mathrm{Cd}$ is zinc and its alloys. Zinc presents a low electrode standard potential $\left(E_{0}=-0.76 \mathrm{~V}\right.$, measured versus hydrogen normal electrode), thus being capable of acting as a sacrificial coating for plated steel parts [4]. The difference between the standard potentials of zinc and the substrate (iron) constitutes the corrosion force of the protection coating in corrosion conditions, and the high value of this difference leads to a rapid dissolution of zinc. The dissolution rate of the protective coating was considerably mitigated by alloying zinc with other elements $(\mathrm{Ni}, \mathrm{Co}, \mathrm{Fe}$, etc.) that shifted the standard electrode potential of the alloy to values closer to the substrate [5]. Among these alloys, the best anticorrosive properties, similar to those of cadmium, are exhibited by the $\mathrm{Zn}-\mathrm{Ni}$ alloy $[6,7]$.

Electrochemical deposition of $\mathrm{Zn}-\mathrm{Ni}$ alloys is an anomalous process by nature. Although $\mathrm{Ni}$ is nobler than $\mathrm{Zn}$, codepositing these metals results in obtaining large quantities of $\mathrm{Zn}$ in the deposited alloy. As an effect of the high $\mathrm{Zn}$ concentration, the alloy dissolution rate is also high in corrosive medium conditions. Various studies and researches were realized for decreasing the anomalous effect of the codeposition and increasing the $\mathrm{Ni}$ content in the alloy, resulting in decreasing the dissolution rate of the anticorrosive alloy coating. These researches focused mainly on using inert species in the deposition bath, to inhibit zinc codeposition, and on developing ternary anticorrosive alloys, such as $\mathrm{Zn}$ $\mathrm{Ni}-\mathrm{X}(\mathrm{X}=\mathrm{Cd}, \mathrm{Co}, \mathrm{P}, \mathrm{Si}$, etc.) $[8,9]$. Among these, ternary Zn$\mathrm{Ni}-\mathrm{P}$ alloys attracted special consideration as an addition of $1-$ $5 \% \mathrm{P}$ considerably enhances the corrosion resistance $[10,11]$.

An efficient and low-cost alternative to the electrodeposition method was developed for obtaining ternary $\mathrm{Zn}-\mathrm{Ni}$ $\mathrm{P}$ alloy coatings and for increasing the $\mathrm{Ni}$ content in the deposited layer.

Electroless deposition is the process of autocatalytic reduction of metals (chemical deposition) in the presence of an oxidizing agent. This method was used for obtaining $\mathrm{Zn}-\mathrm{Ni}$-P coatings from sulphate and chloride solutions. The research performed indicated that the alloy deposition 
TABle 1: Composition of autocatalytic deposition baths.

\begin{tabular}{lccccc}
\hline \multirow{2}{*}{ Deposition bath } & \multicolumn{3}{c}{ Chemical composition (g/L) } \\
& $\mathrm{ZnSO}_{4} \cdot 7 \mathrm{H}_{2} \mathrm{O}$ & $\mathrm{NiSO}_{4} \cdot 6 \mathrm{H}_{2} \mathrm{O}$ & $\mathrm{NaH}_{2} \mathrm{PO}_{2} \cdot \mathrm{H}_{2} \mathrm{O}$ & $\mathrm{C}_{6} \mathrm{H}_{5} \mathrm{Na}_{3} \mathrm{O}_{7} \cdot 2 \mathrm{H}_{2} \mathrm{O}$ & 10 \\
$\mathrm{~A}$ & 5 & 40 & 10 & 10 & 10 \\
$\mathrm{~B}$ & 10 & 40 & 10 & 50 & 10 \\
$\mathrm{C}$ & 20 & 40 & 10 & 50 & 10 \\
\hline
\end{tabular}

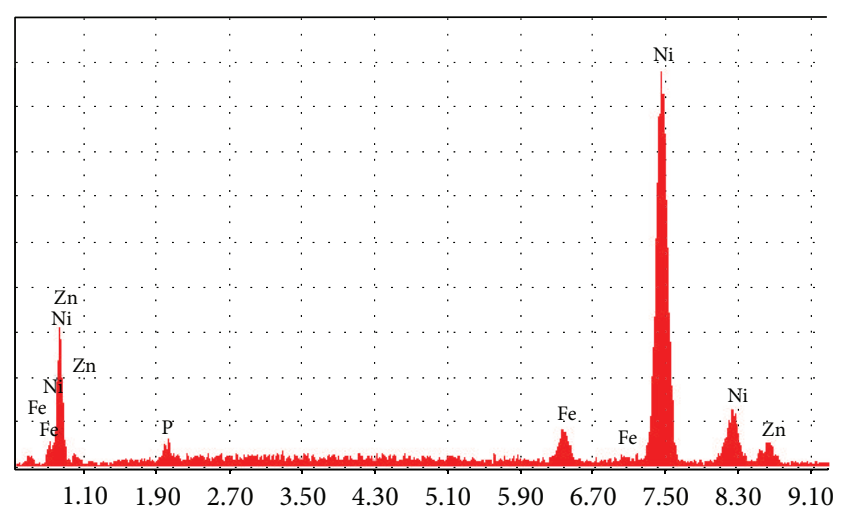

(a)

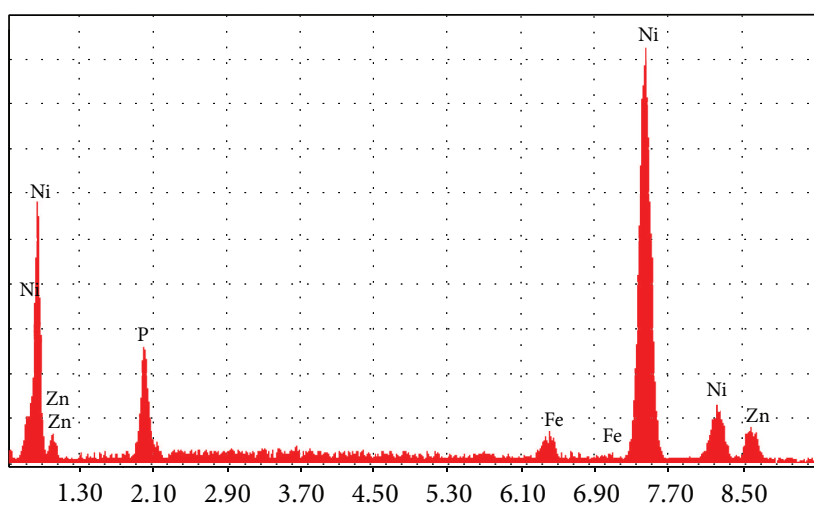

(b)

FIGURE 1: EDAX specters recorded for samples ZNP 1 (a) and ZNP 3 (b).

develops normally, obtaining high concentrations of 70-90\% nickel and zinc concentrations of $10-25 \%$ in the cathodic deposit $[12,13]$. At these elemental concentrations, although the deposited thin film exhibits excellent anticorrosive properties, it cannot be used as a sacrificial coating for steel parts.

The present study presents the experimental works effectuated for autocatalytic obtaining of Ni-Zn-P thin films on steel substrate from sulphate solutions. The effects of deposition bath concentrations and duration of deposition process on physical-chemical and corrosion characteristics of the films obtained are studied.

\section{Experimental Details}

$\mathrm{Ni}-\mathrm{Zn}-\mathrm{P}$ thin films were deposited on carbon steel samples $(\mathrm{C}=0.28$ wt.\% $), 50 \times 25 \times 0.6 \mathrm{~mm}$ in size. Prior to the electroless deposition process, the surface of the steel samples was prepared. This step is necessary because the adherence between the substrate and the coating, with favorable consequences on anticorrosive protection efficiency, can be provided only by adequate preparation of the sample surface. Preparing the substrate for film deposition consisted of polishing on abrasive paper increasing in granulation, acetone degreasing and rinsing in double distilled water, and sample etching, for removing traces of surface adherent oxide, with $50 \% \mathrm{H}_{2} \mathrm{SO}_{4}$ solution at a temperature of $50-60^{\circ} \mathrm{C}$, for $1-2$ minutes, followed by washing with double distilled water. The experimental installation for the electroless deposition consisted of a $600 \mathrm{~cm}^{3}$ thermoresistant vessel and a magnetic heater-stirrer.

The chemical composition of the electroless deposition baths used for the experiments is given in Table 1.
Sodium hypophosphite was used as a reducing agent for the autocatalytic process and also as a phosphorus source in the deposited film. The $\mathrm{pH}$ of the solutions was set and maintained at 10.5 with concentrated $\mathrm{NaOH}$ solution. The electrolytes were prepared using chemical purity solutions and double distilled water.

The thin film deposition was performed at a temperature of $85^{\circ} \mathrm{C}$. The duration of the deposition process was of 1 and $2 \mathrm{~h}$, for each deposition bath used. The deposition bath was stirred at a 30-40 rpm rate using a magnetic agitator.

The obtained thin films were characterized using dispersive X-ray microanalysis (EDAX) for determining the concentration and distribution of the elements and scanning electron microscopy (SEM) for determining the morphology and microstructure. For increasing the accuracy of the elemental distribution assessment, the EDAX analysis was performed in various points situated along a diagonal of the steel parts. The analyses were performed using a XL-30ESEM TMP type electronic microscope, fitted with an EDAX detection device.

For determining corrosion characteristics of obtained films, specific electrochemical analysis methods were used, which permitted the establishing of the corrosion potential $\left(E_{\text {cor }}\right)$, determining polarization resistance, and plotting Tafel polarization curves $[14,15]$.

Corrosion studies were performed on the deposited samples $(50 \times 25 \mathrm{~mm}$ area $)$ using a PARSTAT 2273 potentiostat and the obtained data was processed using specialized "PowerCorr" software. The tests were executed in 3.5\% $\mathrm{NaCl}$ aqueous solution at a $25^{\circ} \mathrm{C}$ temperature, in a threeelectrode electrochemical cell. The steel samples coated with the electrolessly deposited thin film constituted the working electrode and a platinum sheet was used as the cell counter 


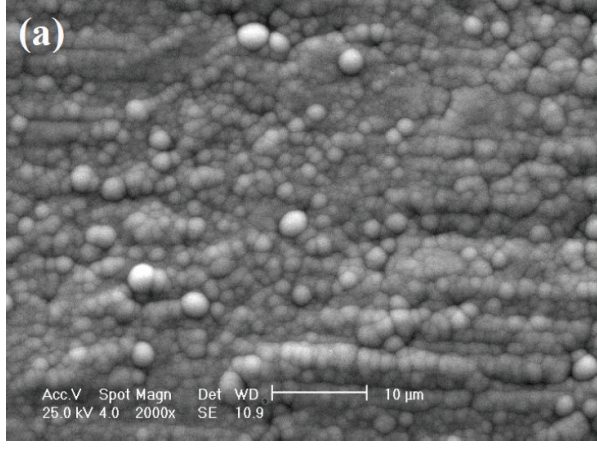

(a)

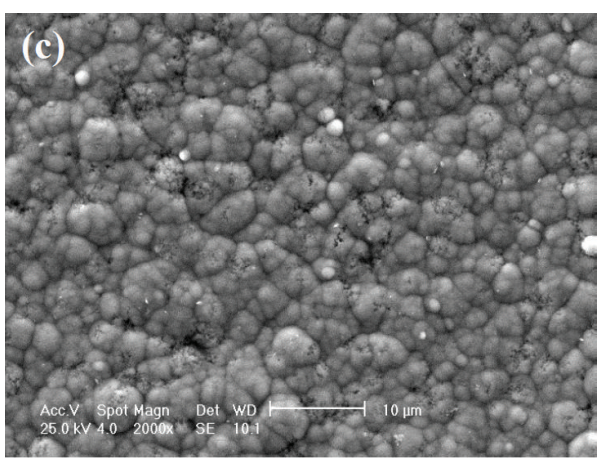

(c)

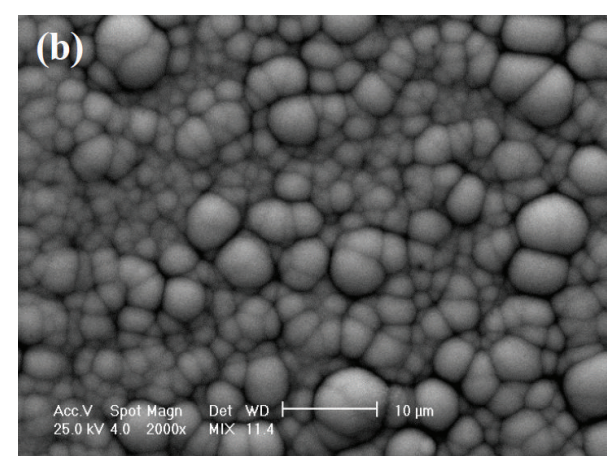

(b)

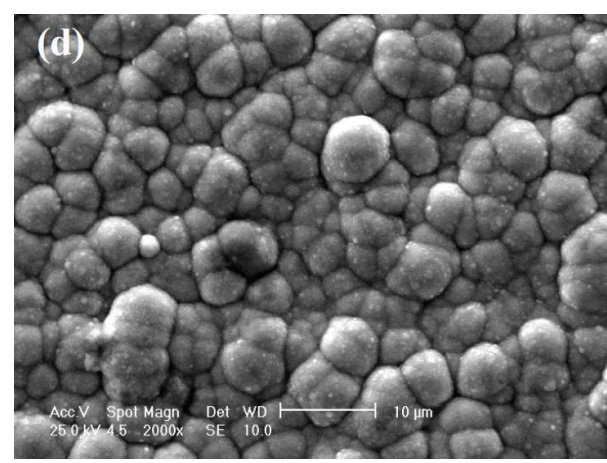

(d)

FigURE 2: SEM micrographs for samples ZNP 1 (a), ZNP 2 (b), ZNP 5 (c), and ZNP 6 (d).

TABLE 2: Elemental chemical composition of deposited thin films.

\begin{tabular}{lccccc}
\hline \multirow{2}{*}{ Sample } & \multirow{2}{*}{ Deposition bath/deposition time } & Coating thickness $(\mu \mathrm{m})$ & \multicolumn{3}{c}{ Chemical composition $($ wt.\%) } \\
& & & Zn & Ni & P \\
\hline ZNP 1 & A/1 hour & 6.3 & 7.95 & 88.18 & 3.07 \\
ZNP 2 & A/2 hours & 8.5 & 8.89 & 89.38 & 1.73 \\
ZNP 3 & B/1 hour & 5.8 & 11.87 & 78.21 & 9.93 \\
ZNP 4 & B/2 hours & 7.9 & 14.73 & 77.79 & 7.48 \\
ZNP 5 & C/1 hour & 7.2 & 16.81 & 76.12 & 7.06 \\
ZNP 6 & C/2 hours & 8.8 & 40.65 & 53.02 & 6.33 \\
\hline
\end{tabular}

TABLE 3: $E_{\mathrm{OPC}}$ potentials measured in open circuit.

\begin{tabular}{lccccccc}
\hline Sample & Steel sample & ZNP 1 & ZNP 2 & ZNP 3 & ZNP 4 & ZNP 5 & ZNP 6 \\
\hline$E_{\text {OPC }}(\mathrm{mV})$ & -619 & -529 & -562 & -520 & -479 & -408 & -389 \\
\hline
\end{tabular}

electrode. A saturated calomel electrode was used as reference electrode. The working electrode potential scanning rate was $0.166 \mathrm{mV} / \mathrm{s}$.

The open circuit potential $\left(E_{\mathrm{OPC}}\right)$ was measured for samples analyzed for 30 minutes. During the open circuit experiments, the free currents generated by exposing the sample to the corrosive medium. were measured depending on time. The polarization resistance determination was effectuated by linear polarization with reduced signal.

The analyzed sample was scanned at $\pm 20 \mathrm{mV}$ versus open circuit potential $E_{\text {OPC }}$. The determination time was 20-30 minutes. For determining Tafel polarization curves (with high signal), the potential was varied in steps, with a step size of $0.166 \mathrm{mV}$, in a $\pm 250 \mathrm{mV}$ versus $E_{\mathrm{OPC}}$ interval, for 12 hours. The obtained data permitted the determination of kinetic parameters for the corrosion process of the studied thin films.

\section{Results and Discussions}

The elemental chemical composition of autocatalytic deposited thin films determined by EDAX is given in Table 2. The energy dispersive $\mathrm{X}$-ray analyses revealed that the chemical composition is almost the same in different areas 
TABLE 4: Kinetic corrosion parameters for the steel substrate and studied samples.

\begin{tabular}{lccccccc}
\hline Sample & $I_{\text {corr }}\left(\mu \mathrm{A} / \mathrm{cm}^{2}\right)$ & $E_{\text {corr }}(\mathrm{V}$ versus SCE $)$ & $\beta_{c}(\mathrm{mV})$ & $\beta_{a}(\mathrm{mV})$ & $R_{p}\left(\Omega \mathrm{cm}^{2}\right)$ & $\mathrm{RC}(\mathrm{mm} / \mathrm{an})$ & $E(\%)$ \\
\hline Steel & 15.260 & -0.554 & 368.48 & 44.93 & 3.768 & 0.358 & 0 \\
ZNP 1 & 4.100 & -0.532 & 11.60 & 21.42 & 74.646 & 0.096 & +73.13 \\
ZNP 2 & 5.630 & -0.534 & 32.16 & 26.95 & 27.892 & +132 \\
ZNP 3 & 8.094 & -0.387 & 48.32 & 39.84 & 13.035 & 0.192 & +63.10 \\
ZNP 4 & 8.201 & -0.490 & 47.55 & 38.64 & 13.173 & 0.192 & +46.95 \\
ZNP 5 & 10.480 & -0.411 & 75.94 & 41.27 & 12.352 & 0.245 \\
ZNP 6 & 12.130 & -0.414 & 84.00 & 42.10 & 14.292 & 0.279 & +31.32 \\
\hline
\end{tabular}

$I_{\text {corr }}$ : corrosion current.

$E_{\text {corr }}$ : corrosion potential.

$\beta_{c}$ and $\beta_{a}$ : Tafel slopes (cathodic and anodic).

$R_{p}$ : polarization resistance.

$\mathrm{RC}$ : corrosion rate.

$E$ : corrosion protection efficiency.

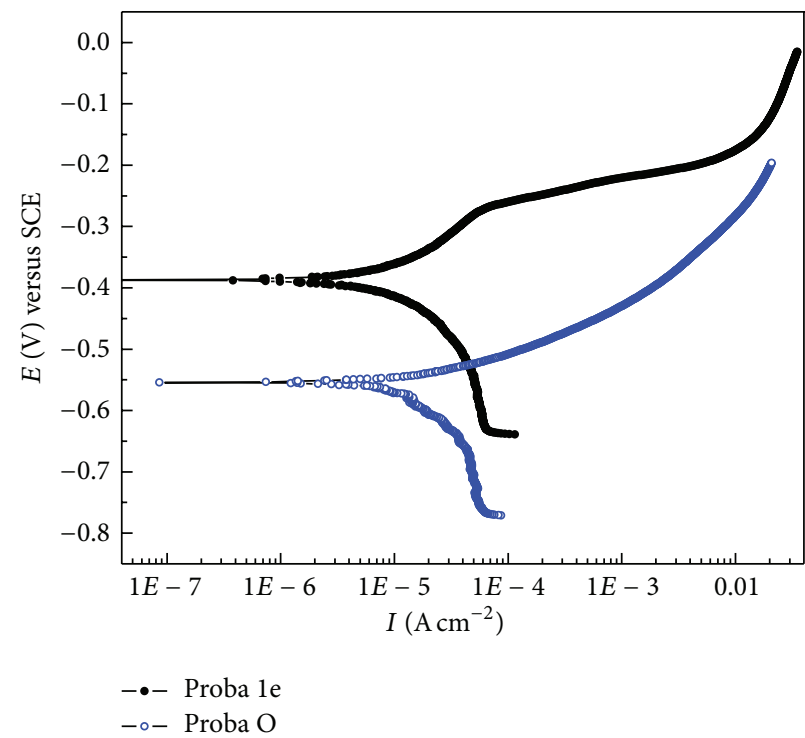

(a)

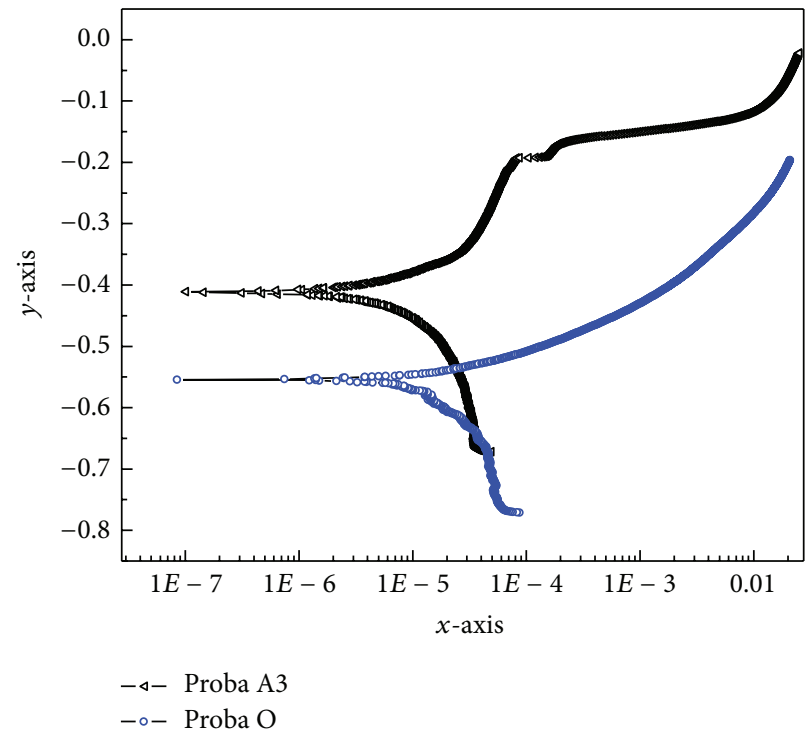

(b)

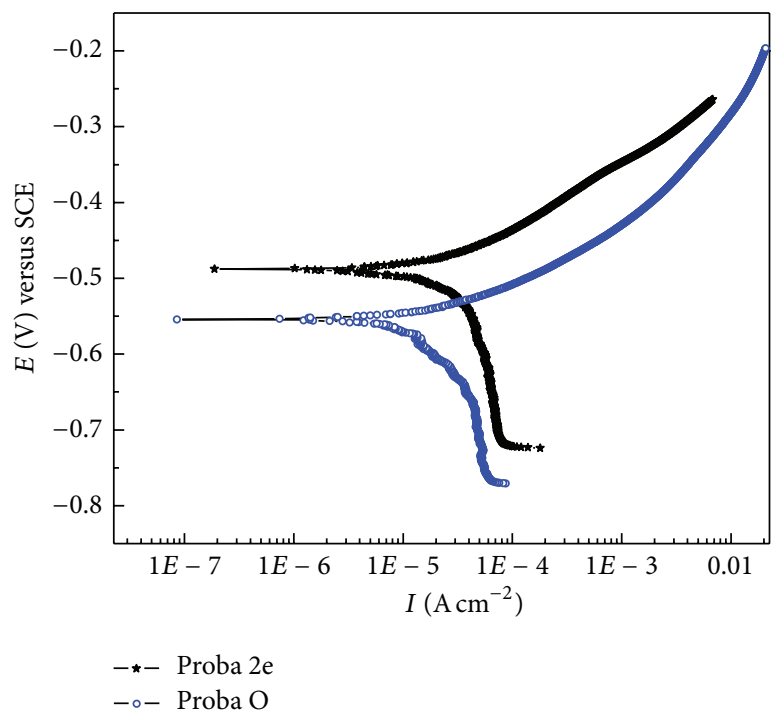

(c)

Figure 3: Tafel curves for samples ZNP 2 (a), ZNP 4 (b), and ZNP 6 (c) (in blue, Tafel curves for uncoated steel sample). 
of the samples. The weight percentages of the thin film elements vary with the zinc content in the deposition bath. Figure 1 presents the EDAX specters recorded for samples ZNP 1 and ZNP 2 and it can be seen that only the Ni, Zn, P, and Fe elements are present, demonstrating the purity of the deposit. The Fe peak is caused by interference between the substrate and the coating [13].

The SEM micrographs for the analyzed samples are presented in Figure 2. By evaluating the obtained results, it can be observed that the obtained Ni-Zn-P coating is light grey and that the surface morphology is homogenous, with uniform distribution of spherical conglomerates (Figures 2(a) and $2(\mathrm{c}))$. As reported elsewhere in literature $[16,17]$, the size of the rounded formations diminishes by increasing the deposition time, as shown in Figures 2(b) and 2(d). As the micrographs show, the deposited film also presents microfissures, gaps, and crevices.

Table 3 contains the values of the $E_{\mathrm{OPC}}$ potential measured in open circuit for the uncoated steel sample and the coated steel samples. The kinetic corrosion parameters are presented in Table 4, measured using the specialized "PowerCorr" software for the uncoated sample and the samples plated with $\mathrm{Ni}-\mathrm{Zn}-\mathrm{P}$ thin films. The Tafel curves plotted for the analyzed film samples and for the uncoated steel sample are presented in Figure 3.

From assessing the data obtained after corrosion tests, it can be observed that the coated samples exhibit higher values for the $I_{\text {corr }}$ corrosion current and a more positive $E_{\mathrm{OPC}}$ open circuit measured potential and corrosion potential than the value measured for the unplated steel sample. The calculated values for the corrosion rates, expressed in $\mathrm{mm} /$ year, are lower than the corrosion rate calculated for the uncoated sample and consequently the corrosion protection efficiency values are higher.

The samples with the highest nickel content in the autocatalytic deposited film, ZNP 1 and ZNP 2, present the highest values for corrosion protection efficiency.

\section{Conclusions}

The experimental results indicated a series of influences of the autocatalytic obtaining conditions on the composition, microstructure structure, and corrosion resistance of Ni-Zn$P$ thin films deposited on carbon steel substrates from alkaline sulphate baths. Thus, the following conclusions can be drawn: the presence of a high $\mathrm{Ni}$ content in the film, decreasing as the immersion time in the deposition bath increases; a zinc content increasing as the content of zinc sulphate in the bath and the time of immersion in the deposition bath increase.

The obtained thin films exhibit a homogenous surface morphology, with an uniform distribution of rounded formations. The conglomeration degree of the spherical formations decreases by increasing the immersion time in the deposition bath.

Steel samples plated with Ni-Zn-P thin films exhibit greater corrosion resistance than the unplated steel sample. The determined values of $I_{\text {corr }}$ corrosion currents ranged in a 4-12 $\mu \mathrm{A}$ interval, comparative to the corrosion current of the uncoated sample, $15 \mu \mathrm{A}$. The highest values for the electrokinetic parameters characterizing the corrosion resistance were recorded for the samples with high $\mathrm{Ni}$ content.

\section{Conflict of Interests}

The author declares that there is no conflict of interests regarding the publication of this paper.

\section{References}

[1] K. R. Baldwin and C. J. E. Smith, "Advances in replacements for cadmium plating in aerospace applications," Transactions of the Institute of Metal Finishing, vol. 74, no. 6, pp. 202-209, 1996.

[2] A. Durairajan, B. S. Haran, R. E. White, and B. N. Popov, "Development of a new electrodeposition process for plating of $\mathrm{Zn}-\mathrm{Ni}-\mathrm{X}(\mathrm{X}=\mathrm{Cd}, \mathrm{P})$ alloys: I. Corrosion characteristics of ZnNi-Cd ternary alloys," Journal of the Electrochemical Society, vol. 147, no. 5, pp. 1781-1786, 2000.

[3] M. M. Abou-Krisha, F. H. Assaf, and A. A. Toghan, "Electrodeposition of Zn-Ni alloys from sulfate bath," Journal of Solid State Electrochemistry, vol. 11, no. 2, pp. 244-252, 2007.

[4] S. Swathirajan, "Potentiodynamic and galvanostatic stripping methods for characterization of alloy electrodeposition process and product," Journal of the Electrochemical Society, vol. 133, no. 4, pp. 671-680, 1986.

[5] N. R. Short, S. Zhou, and J. K. Dennis, "Electrochemical studies on the corrosion of a range of zinc alloy coated steel in alkaline solutions," Surface and Coatings Technology, vol. 79, pp. 218-224, 1996.

[6] Y. Lin and J. R. Selman, "Electrodeposition of corrosionresistant Ni-Zn alloy," Journal of the Electrochemical Society, vol. 140, no. 5, pp. 1299-1303, 1993.

[7] A. Brenner, Electrodeposition of Alloys, Principles and Practice, Academic Press, New York, NY, USA, 1963.

[8] A. M. Popescu, V. Constantin, M. Olteanu, V. Soare, M. Burada, and E. I. Neacsu, "Morphology and corrosion behavior of ZnNi-P thin films electrolessly deposited from chloride baths," Chemistry Magazine, vol. 64, no. 4, pp. 417-424, 2013.

[9] B. Veeraraghavan, H. Kim, and B. Popov, "Optimization of electroless Ni-Zn-P deposition process: experimental study and mathematical modeling," Electrochimica Acta, vol. 49, no. 19, pp. 3143-3154, 2004

[10] Z. Zhou and T. J. O'Keefe, "Modification of anomalous deposition of Zn-Ni alloy by using tin additions," Surface and Coatings Technology, vol. 96, no. 2-3, pp. 191-197, 1997.

[11] E. Valova, I. Georgiev, S. Armyanov et al., "Incorporation of zinc in electroless deposited nickel-phosphorus alloys: I. A comparative study of Ni-P and Ni-Zn-P coatings deposition, structure, and composition," Journal of the Electrochemical Society, vol. 148, no. 4, pp. C266-C273, 2001.

[12] A. Durairajan, A. Krishniyer, B. S. Haran, and B. N. Popov, "Characterization of hydrogen permeation through a corrosion-resistant zinc-nickel-phosphorus alloy," Corrosion, vol. 56 , no. 3, pp. $283-288,2000$.

[13] M. Bouanani, F. Cherkaoui, R. Fratesi, G. Roventi, and G. Barucca, "Microstructural characterization and corrosion resistance of Ni-Zn-P alloys electrolessly deposited from a sulphate bath," Journal of Applied Electrochemistry, vol. 29, no. 5, pp. 637645, 1999. 
[14] S. Zamfir, R. Vidu, and V. Brînzoi, Corrosion of Metallic Materials, Editura Didactica si Pedagogica, Bucharest, Romania, 1994.

[15] I. V. Brînzoi, F. Brînzoi, and L. Pilan, General Characteristics Regarding the Corrosion and Anticorrosive Protection of Metals in Various Media, Printech, Bucharest, Romania, 2006.

[16] O. Hammami, L. Dhouibi, P. Bercot, and E. M. Rezrazi, "Effect of phosphorus doping on some properties of electroplated ZnNi alloy coatings," Surface and Coatings Technology, vol. 219, pp. 119-125, 2013.

[17] Y. Li, P. Kumar, X. Shi, T. A. Nguyen, Z. Xiao, and J. Wu, "Electroless synthesis of Ni-P and Ni-P-Zn alloy coatings for protecting steel rebar from chloride-induced corrosion," International Journal of Electrochemical Science, vol. 7, pp. 81518169, 2012. 

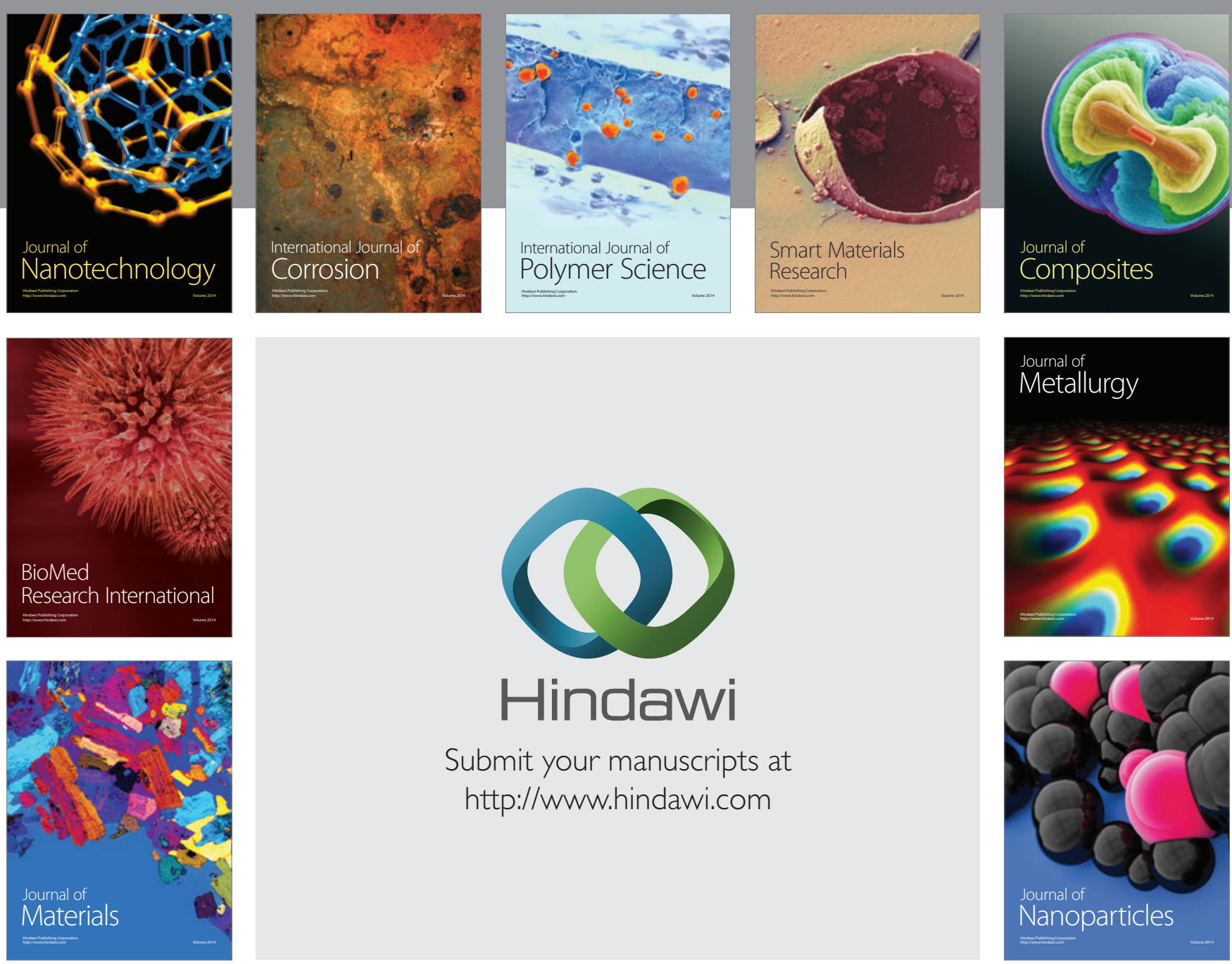

Submit your manuscripts at http://www.hindawi.com
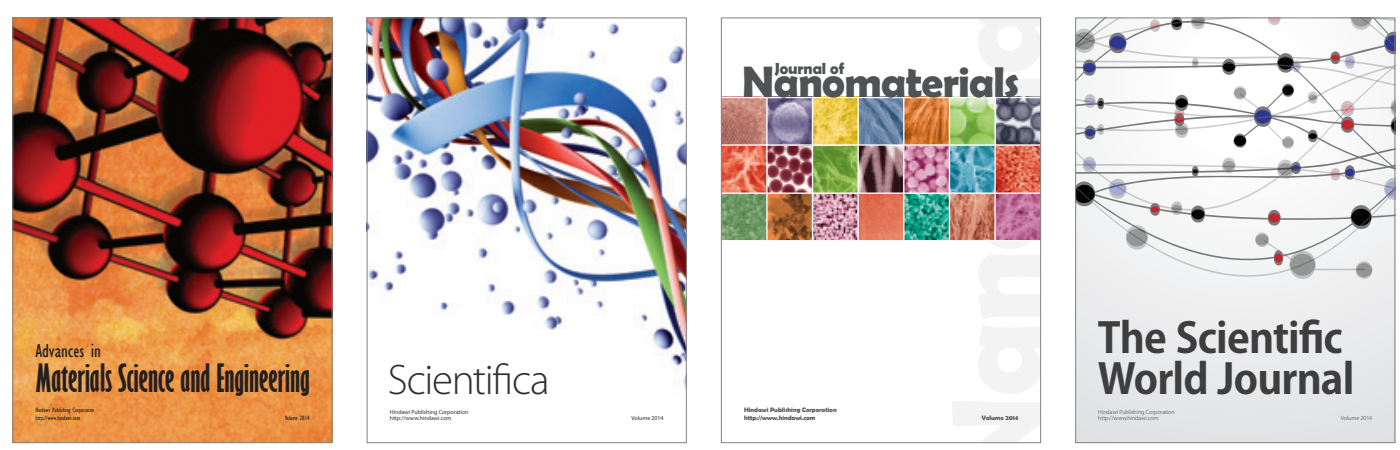

\section{The Scientific World Journal}
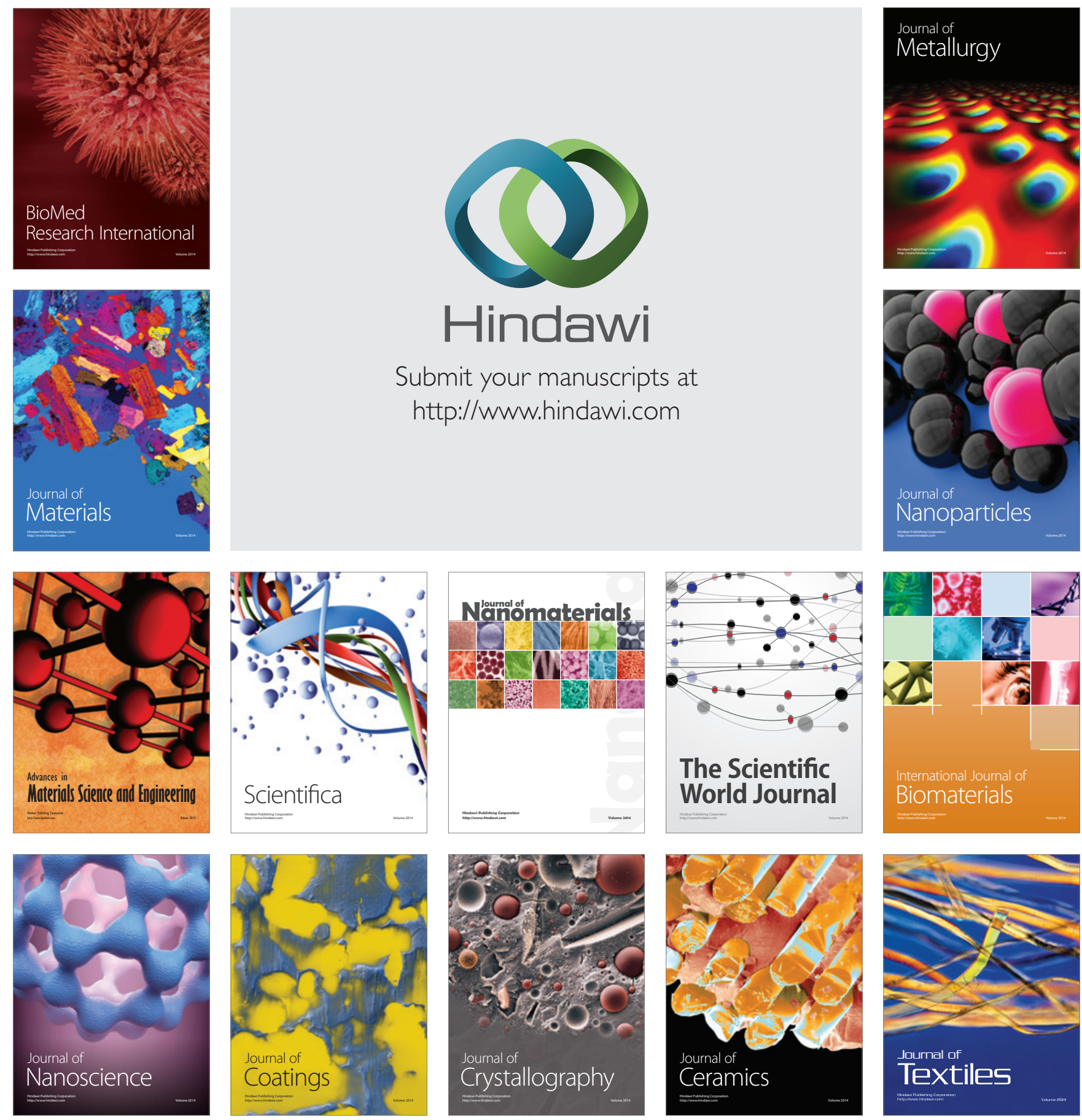